\title{
Successful endoscopic removal of a large colonic lipoma causing intussusception
}

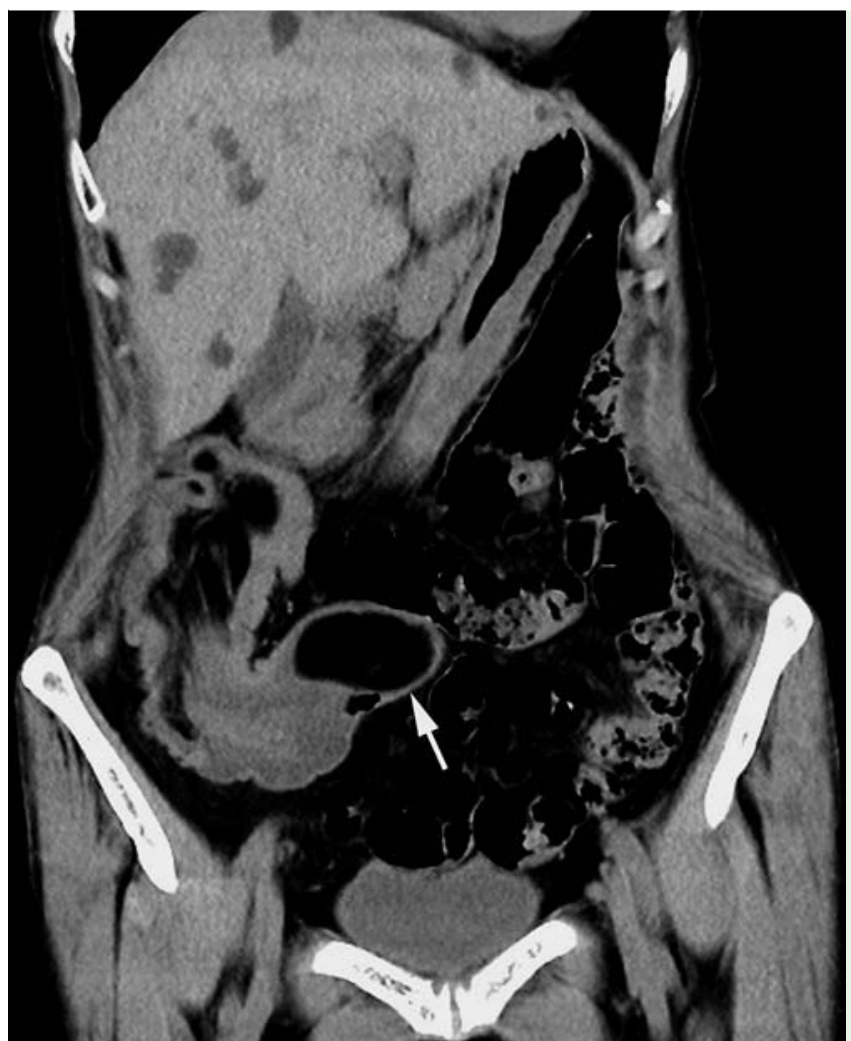

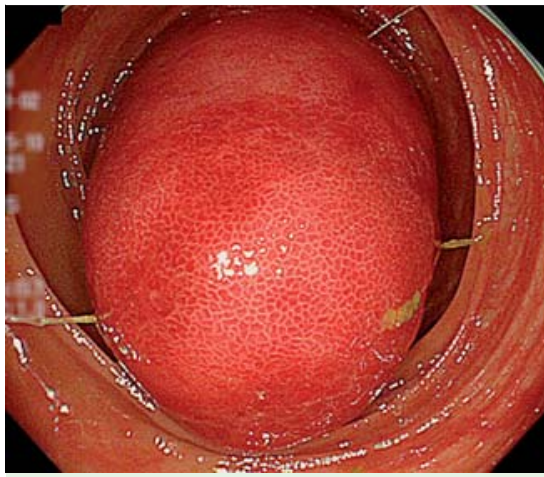

Fig. 2 Colonoscopy shows a large, hyperemic, round mass occupying more than $75 \%$ of the lumen.
A 73-year-old woman presented with symptoms of intermittent abdominal pain without hematochezia. Mild tenderness was noted on palpation over the right iliac fossa; however, all laboratory data, including the C-reactive protein level, were normal. Computed tomography revealed a fatty tissue mass in the transverse colon causing a colonic intus-
Fig. 1 Computed tomography shows a fatty tissue mass (arrow) in the transverse colon that is causing a colonic intussusception.



Fig. 3 Endoscopic ultrasonography shows a hyperechoic mass (arrows) in the submucosal layer. diagnosis was ascending-transverse colonic intussusception caused by a large lipoma originating at the ileocecal valve. Because of its shape, the endoscopic mucosal resection technique could be used to remove the lipoma without complications ( Fig.5). The lesion was captured with a snare (SD-210U-25; Olympus Medical Systems Corp., Tokyo, Japan) after saline had been injected. Electrocautery (forced coagulation) was applied to cut the lesion. The resected specimen was a large submucosal tumor, $55 \times 30 \times 22 \mathrm{~mm}$ in size, with a yellowish cut surface ( Fig.6). Histopathology indicated proliferating fat cells in the submucosal layer, and a lipoma was diagnosed. The patient was discharged from the hospital 5 days after treatment.

Lipomas are benign, nonepithelial tumors that occur throughout the gastrointestinal tract, but typically in the colon. Lipomas larger than $2 \mathrm{~cm}$ in diameter can cause intussusception, obstruction, or bleeding [1]. Although frequent in children, intestinal intussusception is unusual in adults. A colonic lipoma as the principal point for colonic intussusception is uncommon [2]. Endoscopic methods to remove ileocolonic lipoma have been reported previously [3-6]. However, to our knowledge, the endoscopic removal of a lipoma causing a definite intussusception has not been reported. In previous case reports, most patients with colonic lipoma intussusception have undergone surgical treatment. Endoscopic removal, which is less invasive, may be another option for the treatment of large colonic lipomas.

Endoscopy_UCTN_Code_CPL_1AJ_2AD

Competing interests: None

\section{Ryo Kosaka', Tomohiro Noda', Junya Tsuboi', Kyosuke Tanaka ${ }^{2}$}

${ }^{1}$ Department of Gastroenterology, Matsusaka City Hospital, Matsusaka, Japan

2 Department of Endoscopic Medicine, Mie University Hospital, Tsu, Japan

susception ( $\bullet$ Fig. 1). Colonoscopy revealed a large mass in the ascending colon (๑ Fig.2). Endoscopic ultrasonography revealed a hyperechoic mass in the submucosal layer ( Fig.3). On the contrast radiograph, the semipedunculated mass was seen to arise from the ileocecal valve; the intussusception was disinvaginated by inserting the colonoscope ( Fig.4). The

\section{References}

1 Pfeil SA, Weaver MG, Abdul-Karim FW et al Colonic lipomas: outcome of endoscopic removal. Gastrointest Endosc 1990; 36: 435 438

2 Rogers SO Jr, Lee MC, Ashley SW. Giant colonic lipoma as lead point for intermittent colo-colonic intussusception. Surgery 2002; 131: $687-688$ 




Fig. 4 Contrast radiograph shows the large colonic mass to be semipedunculated.



Fig. 5 The mass is removed endoscopically without perforation.
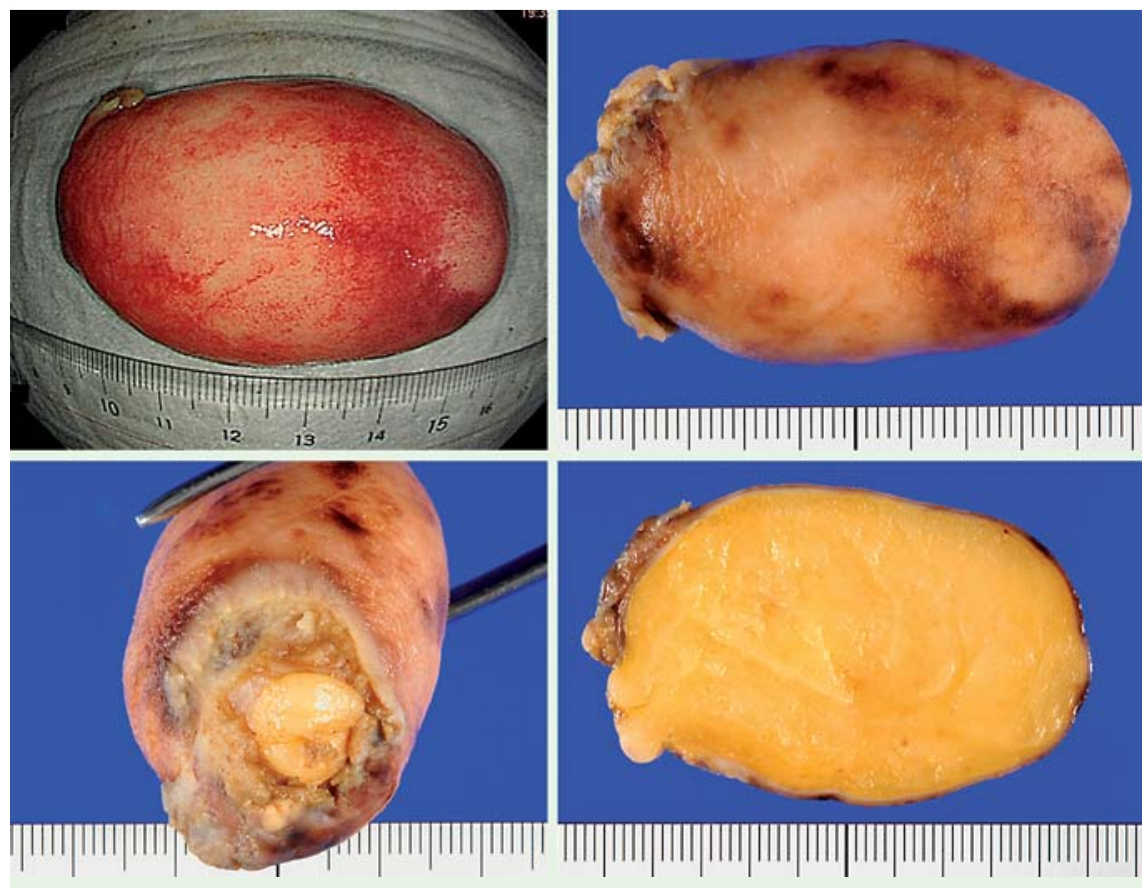

Fig. 6 The resected specimen is a large submucosal tumor, $55 \times 30 \times 22 \mathrm{~mm}$ in size, with a yellowish cut surface.

3 Bar-Meir S, Halla A, Baratz M. Endoscopic removal of colonic lipoma. Endoscopy 1981; 13: $135-136$

4 Raju GS, Gomez G. Endoloop ligation of a large colonic lipoma: a novel technique. Gastrointest Endosc 2005; 62: 988-990

5 Morimoto T, Fu KI, Konuma $\mathrm{H}$ et al. Peeling a giant ileal lipoma with endoscopic unroofing and submucosal dissection. World J Gastroenterol 2010; 16: 1676-1679

6 Ivekovic $H$, Rustemovic $N$, Brkic T et al. Endoscopic ligation ("Loop-And-Let-Go") is effective treatment for large colonic lipomas: a prospective validation study. BMC Gastroenterol 2014; 14: 122

\section{Bibliography}

DOI http://dx.doi.org/

10.1055/s-0034-1377953

Endoscopy 2014; 46: E551-E552

(c) Georg Thieme Verlag KC

Stuttgart · New York

ISSN 0013-726X

\section{Corresponding author}

\section{Kyosuke Tanaka, MD, PhD}

Department of Endoscopic Medicine

Mie University Hospital

2-174 Edobashi, Tsu, Mie

514-8507 Japan

Fax: +81-59-231-5285

kyosuket@qa2.so-net.ne.jp 